\title{
ANALISA STEADY STATE ERROR SISTEM KONTROL LINIER INVARIANT WAKTU
}

\author{
FANNY YULIA SARI \\ Program Studi Matematika, \\ Fakultas Matematika dan Ilmu Pengetahuan Alam, Universitas Andalas, \\ Kampus UNAND Limau Manis Padang, Indonesia, \\ fani_yes@yahoo.com
}

\begin{abstract}
Abstrak. Dalam penelitian ini akan dikaji steady state error sistem kontrol linier invariant waktu, khususnya untuk permasalah feedback kontrol, yang mana jika diberikan input baru fungsi tangga satuan dan output pada steady state tidak sama dengan perilaku input. Kajian ini dimulai dari menghitung error sistem yang telah stabil dan mencapai steady state, selanjutnya error yang ada akan dieleminir dengan penambahan kontrol integral.
\end{abstract}

Kata Kunci: Sistem persamaan linier, transformasi Laplace, fungsi Transfer

\section{Pendahuluan}

Sistem kontrol (control system) merupakan suatu alat untuk mengendalikan dan mengatur keadaan dari suatu sistem. Dalam merancang suatu sistem kontrol, perancang harus dapat meramalkan perilaku dinamis sistem yang dirancang tersebut dengan mengetahui perilaku komponen-komponen yang terkait. Karakteristik utama tentang perilaku dinamis dari suatu sistem kontrol adalah kestabilan, yaitu apakah sistem tersebut stabil atau tidak [4].

Untuk suatu sistem kontrol invariant waktu,

$$
\begin{aligned}
\dot{\mathbf{x}}(t) & =A \mathbf{x}(t)+B \mathbf{u}(t) \\
\mathbf{y}(t) & =C \mathbf{x}(t)
\end{aligned}
$$

di mana $\mathbf{x}(t) \in \mathbb{R}^{n}$ menyatakan vektor keadaan, $\mathbf{u}(t) \in \mathbb{R}^{m}$ menyatakan vektor input, $\mathbf{y}(t) \in \mathbb{R}^{p}$ menyatakan vektor output (respon), $A \in \mathbb{R}^{n \times n}, B \in \mathbb{R}^{n \times m}$, dan $C \in \mathbb{R}^{p \times n}$, kestabilannya diperlihatkan oleh perilaku output bila $t \rightarrow \infty$. Suatu sistem dikatakan mencapai steady state jika sistem dapat mempertahankan kestabilannya pada saat $t \rightarrow \infty$.

Karena suatu sistem kontrol melibatkan penyimpanan energi, maka output tidak dapat langsung mengikuti perilaku input tetapi dapat memperlihatkan respon peralihan (transient response) sebelum sistem mencapai kestabilannya. Respon peralihan ini dapat menyebabkan error pada sistem. Jika output pada steady state tidak sama dengan perilaku input, maka sistem dikatakan berada dalam keadaan error (steady state error). 


\section{Menghitung Nilai Error}

Sebelum menganalisa steady state error terlebih dahulu perlu diketahui output dari sistem. Setelah output diperoleh, untuk menganalisa steady state error dari output sistem terhadap suatu input tertentu diperlukan teorema nilai akhir. Jika $\mathcal{F}(s)$ adalah transformasi Laplace dari $f(t)$ dan jika $\lim _{t \rightarrow \infty} f(t)$ ada, maka $\lim _{t \rightarrow \infty} f(t)=\lim _{s \rightarrow 0} s \mathcal{F}(s)$ [4]. Dalam menganalisa steady state error diasumsikan sistem (1.1) telah stabil dengan suatu kontrol feedback

$$
\mathbf{u}(t)=-K \mathbf{x}
$$

untuk suatu $K \in \mathbb{R}^{m \times n}$. Gambar 2.1 berikut memperlihatkan perilaku sistem kontrol feedback. Selanjutnya, akan diselidiki error dari sistem tersebut jika diberikan

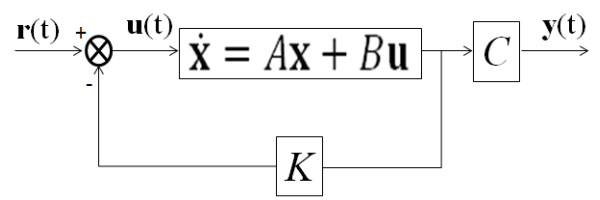

Gambar 2.1. Diagram Blok Sistem 1.1

suatu input $\mathbf{r}(t)$. Sebagaimana yang telah diuraikan sebelumnya bahwa error dari sistem akan ada jika perilaku output pada steady state tidak sama dengan input, dengan kata lain error merupakan selisih antara output dan input, yaitu

$$
\mathbf{e}(t)=\mathbf{r}(t)-\mathbf{y}(t)
$$

Besarnya error ini dapat dihitung dengan mengambil transformasi Laplace dari sistem (2.2), yaitu

$$
\begin{aligned}
\mathcal{E}(s) & =\mathcal{R}(s)-\mathcal{Y}(s) \\
& =\mathcal{R}(s)-\left[C(s I-A)^{-1} B\right] \mathcal{R}(s) \\
& =\left[I-C(s I-A)^{-1} B\right] \mathcal{R}(s) .
\end{aligned}
$$

di mana $\mathcal{E}(s), \mathcal{R}(s)$ dan $\mathcal{Y}(s)$ berturut-turut merupakan transformasi Laplace dari $\mathbf{e}(t), \mathbf{r}(t)$ dan $\mathbf{y}(t)$. Selanjutnya, dengan menggunakan teorema nilai akhir, steady state error, $e_{s s}$, untuk sistem (1.1) adalah

$$
\begin{aligned}
e_{s s} & =\lim _{t \rightarrow \infty} \mathbf{e}(t) \\
& =\lim _{s \rightarrow 0} s \mathcal{E}(s) \\
& =\lim _{s \rightarrow 0} s\left[I-C(s I-A)^{-1} B\right] \mathcal{R}(s) \\
& =\lim _{s \rightarrow 0}\left[I-C(s I-A)^{-1} B\right] s \mathcal{R}(s) .
\end{aligned}
$$

Jika $\mathbf{r}(t)$ merupakan fungsi tangga satuan, yaitu

$$
\mathcal{R}(s)=\frac{1}{s},
$$


maka error sistem (1.1) adalah

$$
\begin{aligned}
e_{s s} & =\lim _{s \rightarrow 0}\left[I-C(s I-A)^{-1} B\right] s \mathcal{R}(s) \\
& =\lim _{s \rightarrow 0}\left[I-C(s I-A)^{-1} B\right] s\left(\frac{1}{s}\right) \\
e_{s s} & =\lim _{s \rightarrow 0}\left[I-C(s I-A)^{-1} B\right] .
\end{aligned}
$$

Jika disubstitusikan $s=0$ maka $H(0)=-C A^{-1} B$ sehingga diperoleh error dengan input fungsi tangga satuan [3],

$$
e_{s s}=I+C A^{-1} B
$$

\section{Mengeliminir Nilai Error}

Untuk memperkecil steady state error dapat dilakukan dengan menaikkan pangkat dari bentuk karakteristik sistem dengan menambahkan satu atau lebih kontrol integral (integrator) pada lintasan umpan maju. Dalam kasus ini kontrol integral yang digunakan adalah $K_{e} \mathbf{x}_{N}$ dengan $\mathbf{x}_{N}(t) \in \mathbb{R}^{p}$ dan $K_{e} \in \mathbb{R}^{m \times p}$ [3]. Situasi ini diperlihatkan pada Gambar 3.1 berikut. Dari Gambar 3.1, yang menyebabkan error

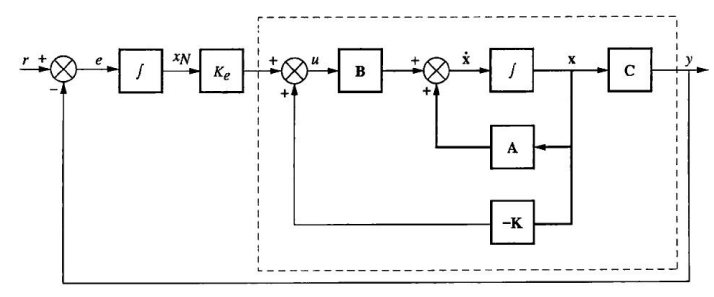

Gambar 3.1. Diagram Blok dengan Kontrol Integral

adalah

$$
\dot{\mathbf{x}}_{N}(t)=\mathbf{r}(t)-C \mathbf{x}(t),
$$

dan memiliki pengontrol sebagai berikut

$$
\begin{aligned}
\mathbf{u}(t) & =-K \mathbf{x}(t)+K_{e} \mathbf{x}_{N}(t) \\
& =-\left(K-K_{e}\right)\left(\begin{array}{c}
\dot{\mathbf{x}} \\
\dot{\mathbf{x}}_{N}
\end{array}\right) .
\end{aligned}
$$

Dengan menggabungkan persamaan (1.1) dan (3.1) diperoleh

$$
\begin{aligned}
\left(\begin{array}{c}
\dot{\mathbf{x}} \\
\dot{\mathbf{x}}_{N}
\end{array}\right) & =\left(\begin{array}{cc}
A & 0 \\
-C & 0
\end{array}\right)\left(\begin{array}{c}
\mathbf{x} \\
\mathbf{x}_{N}
\end{array}\right)+\left(\begin{array}{c}
B \\
0
\end{array}\right) u+\left(\begin{array}{l}
0 \\
1
\end{array}\right) r \\
\mathbf{y}(t) & =\left(\begin{array}{lll}
C & 0
\end{array}\right)\left(\begin{array}{c}
\mathbf{x} \\
\mathbf{x}_{N}
\end{array}\right) .
\end{aligned}
$$


Selanjutnya, substitusikan persamaan (3.2) ke persamaan (3.3) diperoleh

$$
\begin{aligned}
\left(\begin{array}{c}
\dot{\mathbf{x}} \\
\dot{\mathbf{x}}_{N}
\end{array}\right) & =\left(\begin{array}{cc}
A_{c l} & B K_{e} \\
-C & 0
\end{array}\right)\left(\begin{array}{c}
\mathbf{x} \\
\mathbf{x}_{N}
\end{array}\right)+\left(\begin{array}{l}
0 \\
1
\end{array}\right) r \\
\mathbf{y}(t) & =\left(\begin{array}{ll}
C & 0
\end{array}\right)\left(\begin{array}{c}
\mathbf{x} \\
\mathbf{x}_{N}
\end{array}\right) .
\end{aligned}
$$

dengan $A_{c l}=A-B K$. Persamaan (3.4) merupakan persamaan ruang keadaan sistem linier invarian waktu yang telah ditambah kontrol integral [3].

\section{Penerapan}

Diberikan sistem linier kontinu sebagai berikut

$$
\begin{aligned}
\dot{\mathbf{x}}(t) & =\left(\begin{array}{cc}
-2 & 1 \\
1 & -2
\end{array}\right) \mathbf{x}(t)+\left(\begin{array}{l}
0 \\
1
\end{array}\right) \mathbf{u}(t) \\
y(t) & =\left(\begin{array}{ll}
4 & 1
\end{array}\right) \mathbf{x}(t)
\end{aligned}
$$

a. Hitunglah steady state error dari sistem (4.1) dengan input fungsi tangga satuan.

b. Hitunglah steady state error dari sistem (4.1) dengan mengulangi pengontrolan [a] dan menambah kontrol integral.

\section{Jawab}

a. Untuk menentukan output sistem diperlukan nilai eigen dan vektor eigen dari sistem (4.1). Adapun nilai eigennya adalah $-1,-3$ dan vektor eigen yang berkaitan dengan nilai eigen secara berturut-turut sebagai berikut

$$
\left(\begin{array}{l}
1 \\
1
\end{array}\right),\left(\begin{array}{c}
-1 \\
1
\end{array}\right) \text {. }
$$

Solusi sistem (4.1) adalah

$$
\mathbf{x}(t)=-\frac{1}{2}\left(\begin{array}{l}
1 \\
1
\end{array}\right) e^{-t}-\frac{1}{6}\left(\begin{array}{c}
-1 \\
1
\end{array}\right) e^{-3 t}+\left(\begin{array}{c}
\frac{1}{3} \\
\frac{2}{3}
\end{array}\right) .
$$

Selanjutnya, substitusikan persamaan (4.2) kedalam output pada sistem (4.1), yang memberikan hasil sebagai berikut

$$
y=\frac{-5}{2} e^{-t}+\frac{1}{2} e^{-3 t}+2 .
$$

Persamaan (4.3) menghasilkan output sebagai pada Gambar 4.1 berikut.

Dari kurva output terlihat ada error pada sistem. Untuk menghitung error dari sistem (4.1) digunakan persamaan (2.8).

$$
\begin{aligned}
e_{s s} & =I+\left(C A^{-1} B\right) \\
& =I+\left(\begin{array}{ll}
4 & 1
\end{array}\right)\left(\begin{array}{cc}
-2 & 1 \\
1 & -2
\end{array}\right)^{-1}\left(\begin{array}{l}
0 \\
1
\end{array}\right) \\
& =1+(-2) \\
& =-1 .
\end{aligned}
$$




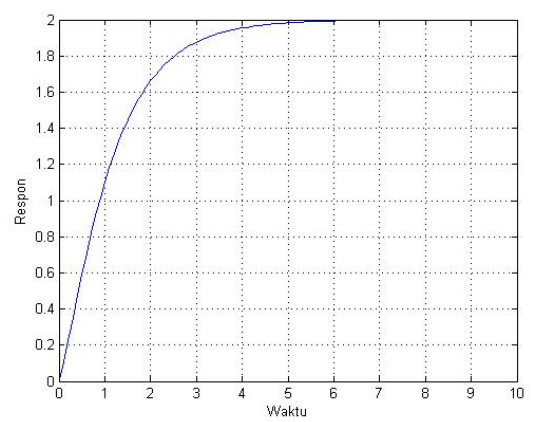

Gambar 4.1. Respon Sistem 4.1

b. Pengontrolan dengan penambahan kontrol integral. Dengan menggunakan persamaan (3.4) maka ruang keadaan sistem (4.1) menjadi

$$
\begin{aligned}
& \left(\begin{array}{c}
\dot{x}_{1} \\
\dot{x}_{2} \\
\dot{x}_{N}
\end{array}\right)=\left(\begin{array}{cc}
{\left[\begin{array}{cc}
-2 & 1 \\
1 & -2
\end{array}\right]-\left[\begin{array}{l}
0 \\
1
\end{array}\right]\left[\begin{array}{ll}
K_{1} & K_{2}
\end{array}\right]} & \mid\left[\begin{array}{l}
0 \\
1
\end{array}\right] K_{e} \\
------------------- \\
-\left[\begin{array}{ll}
4 & 1
\end{array}\right] & 0
\end{array}\right)\left(\begin{array}{l}
x_{1} \\
x_{2} \\
x_{N}
\end{array}\right) \\
& +\left(\begin{array}{l}
0 \\
0 \\
1
\end{array}\right) \mathbf{r} \\
& =\left(\begin{array}{ccc}
-2 & 1 & 0 \\
\left(1-K_{1}\right) & \left(-2-K_{2}\right) & K_{e} \\
-4 & -1 & 0
\end{array}\right)\left(\begin{array}{c}
x_{1} \\
x_{2} \\
x_{N}
\end{array}\right)+\left(\begin{array}{l}
0 \\
0 \\
1
\end{array}\right) \mathbf{r} \\
& \mathbf{y}=\left(\begin{array}{lll}
4 & 1 & 0
\end{array}\right)\left(\begin{array}{c}
x_{1} \\
x_{2} \\
x_{N}
\end{array}\right)
\end{aligned}
$$

Persamaan karakteristik dari persamaan (4.4) adalah

$$
s^{3}+\left(K_{2}+4\right) s^{2}+\left(K_{1}+2 K_{2}+K_{e}\right) s+6 K_{e}=0 .
$$

Selanjutnya, pilih nilai eigen yang ketiga dari sistem awal, yaitu $(s+2)$ maka persamaan karakteristik dari sistem (4.1) adalah

$$
(s+2)\left(s^{2}+4 s+3\right)=0
$$

Dengan membandingkan persamaan (4.5) dan (4.6) diperoleh

$$
\begin{aligned}
& K_{1}=3 \\
& K_{2}=2 \\
& K_{e}=1 .
\end{aligned}
$$

Substitusikan nilai $K_{1}, K_{2}$, dan $K_{e}$ kedalam persamaan (4.4) maka diper- 
oleh persamaan ruang keadaan

$$
\begin{aligned}
\left(\begin{array}{c}
\dot{x}_{1} \\
\dot{x}_{2} \\
\dot{x}_{N}
\end{array}\right) & =\left(\begin{array}{ccc}
-2 & 1 & 0 \\
-2 & -4 & 1 \\
-4 & -1 & 0
\end{array}\right)\left(\begin{array}{l}
x_{1} \\
x_{2} \\
x_{N}
\end{array}\right)+\left(\begin{array}{l}
0 \\
0 \\
1
\end{array}\right) \mathbf{r} \\
\mathbf{y} & =\left(\begin{array}{lll}
4 & 1 & 0
\end{array}\right)\left(\begin{array}{c}
x_{1} \\
x_{2} \\
x_{N}
\end{array}\right)
\end{aligned}
$$

Sebelum menentukan error perlu diperlihatkan output sistem (4.7), untuk menentukan output sistem diperlukan nilai eigen dan vektor eigen dari sistem tersebut. Adapun nilai eigennya adalah $-1,-2,-3$ dan vektor eigen yang berkaitan dengan nilai eigen secara berturut-turut sebagai berikut

$$
\left(\begin{array}{c}
0.2 \\
0.2 \\
1
\end{array}\right),\left(\begin{array}{c}
0.5 \\
0 \\
1
\end{array}\right),\left(\begin{array}{c}
1 \\
-1 \\
1
\end{array}\right) .
$$

Solusi sistem (4.4) adalah

$$
\begin{aligned}
\mathbf{x}(t)=\left(\begin{array}{c}
0.5648 \\
0.5648 \\
2.824
\end{array}\right) e^{-t} & +\left(\begin{array}{c}
-1.329 \\
0 \\
-2.658
\end{array}\right) e^{-2 t} \\
& +\left(\begin{array}{c}
0.498 \\
-0.498 \\
0.498
\end{array}\right) e^{-3 t}+\left(\begin{array}{c}
0.2662 \\
-0.0668 \\
0.664
\end{array}\right) .
\end{aligned}
$$

Selanjutnya, substitusikan persamaan (4.8) kedalam (4.7) yang memberikan hasil sebagai berikut.

$$
y=2.824 e^{-t}-5.316 e^{-2 t}+1.494 e^{-3 t}+0.998 .
$$

Output dari sistem (4.7) digambarkan pada kurva berikut

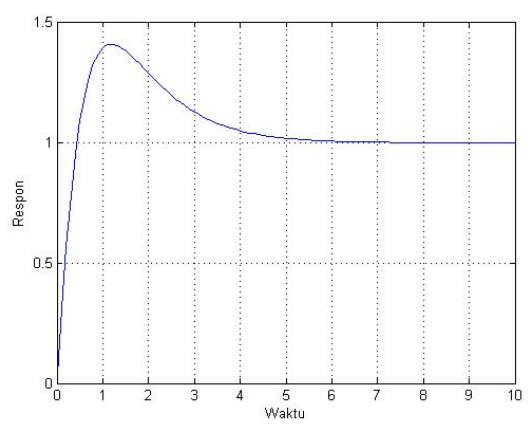

Gambar 4.2. Respon Sistem (4.7) 
Dari ruang keadaan (4.7) menghasilkan error sebagai berikut

$$
\begin{aligned}
e_{s s} & =I+\left(C A^{-1} B\right) \\
& =I+\left[\left(\begin{array}{lll}
4 & 1 & 0
\end{array}\right)\left(\begin{array}{ccc}
-2 & 1 & 0 \\
-2 & -4 & 1 \\
-4 & -1 & 0
\end{array}\right)^{-1}\left(\begin{array}{l}
0 \\
0 \\
1
\end{array}\right)\right] \\
& =1+(-1) \\
& =0 .
\end{aligned}
$$

Dengan membandingkan kedua output yang dihasilkan dapat disimpulkan bahwa sistem yang ditambah kontrol integral tidak memiliki error.

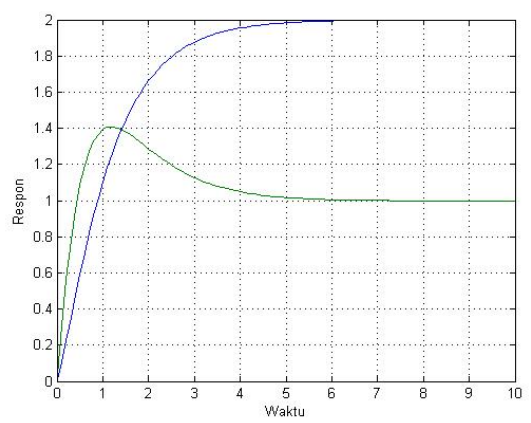

Gambar 4.3. Kurva Gabungan

\section{Ucapan Terima kasih}

Penulis mengucapkan terima kasih kepada Bapak Dr. Muhafzan, Bapak Narwen, M. Si, Bapak Dr. Admi Nazra, Bapak Zulakmal, M.Si yang telah memberikan masukan dan saran sehingga paper ini dapat diselesaikan dengan baik.

\section{Daftar Pustaka}

[1] Anton, H. 1991. Aljabar Linier Elementer, Edisi Kedelapan-Jilid 1. Erlangga, Jakarta

[2] Boyce, W. E, Diprima, R. C. 2001. Elementary Differential Equation and Boundary Value Problem. John Wiley \& Sons, Inc. USA

[3] Nise, Norman S. 2011. Control Systems Engineering, Sixth Edition. John Wiley \& Sons, Inc. USA

[4] Ogata, K. 2002. Modern Control Engineering, Fourth Editon. Prentice-Hall, New Jersey 